\title{
Altruism, honesty and religiosity in nursing students
}

\author{
Fiona Timmins PhD, MSc, MA, Associate Professor ${ }^{1}$ (D) | Carole King MSc, RCN, RNT, \\ Assistant Professor ${ }^{1}$ | Jan MA de Vries PhD, MSc, MA, Assistant Professor and Psychology \\ Subject Leader $^{1}$ | Martin Johnson PhD, MSc, RN, Professor in Nursing ${ }^{2}$ | John G Cullen \\ PhD, MA, MLIS, Senior Lecturer ${ }^{3}$ | Carol Haigh PhD, RN, Professor ${ }^{4}$
}

${ }^{1}$ School of Nursing and Midwifery, Trinity College Dublin, Dublin, Ireland

${ }^{2}$ School of Nursing, Midwifery, Social Work and Social Science, University of Salford,

Salford, UK

${ }^{3}$ Maynooth University School of Business, Co. Kildare, Ireland

${ }^{4}$ Department of Nursing, Midwifery, Manchester Metropolitan University,

Manchester, UK

Correspondence

Fiona Timmins, School of Nursing and Midwifery, Trinity College Dublin, Dublin, Ireland

Email: timminsf@tcd.ie
Aims and objectives: To identify, at different stages of nursing education, the extent to which nursing students appreciate altruism, honesty, religiosity and other, sometimes contrasting, values in practice.

Background: Nursing is informed by values that guide care ethos and activities. Embodiment of these core values has become a matter of concern. Reports outlining deficiencies in health care followed by polemics in nursing journals have called into question whether nursing students are sufficiently motivated by values and educated in their application. This study explores these values among undergraduate nursing students in the Republic of Ireland. Considering the strong religious tradition in health care in Ireland, religiosity was also included.

Design: A link to an online survey was distributed via email to all nursing students in the thirteen Schools of Nursing in the Republic of Ireland.

Method: Quantitative data were collected using an adaptation of the SalfordScott (Journal of Advanced Nursing, 57(8), 2007, 366) Nursing Values Questionnaire.

Results: Participants ( $n=158$ ) reported positively to statements related to honesty and altruism. Both altruism and religiosity received support, but the latter was to a lesser extent. Students considered their professionalism more important than altruism, and honesty varied according to the situation.

Conclusions: This study adds new information by confirming that students exhibit support for two of the most essential values in nursing: altruism and honesty. The adapted Salford-Scott instrument has shown reliability and promise in further empirical study in nursing.

Relevance to clinical practice: Priority given to professionalism over altruism reflects concerns highlighted in the international literature around overly taskoriented care in which compassion gets lost. Also, when loyalty supersedes honesty, problems with accountability in health care may emerge. Uncertainty around religiosity in health care may reflect limitations in competence in nurses to relate to patients with religions or spirituality other than their own. 


\section{KEYWORDS}

altruism, honesty, nurse, nursing student, religion, Salford-Scott Nursing Values Questionnaire, spirituality, values

\section{1 | INTRODUCTION}

In this series, the Journal of Clinical Nursing aims to draw attention to fundamental nursing care and identify current gaps in service provision internationally. Somewhat ironically termed "the last evidencefree zone", fundamental aspects of nursing care, while considered essential by both the public and the profession, remain "poorly defined and inadequately described and studied" (Kitson, Sørensen, Jeffs, \& Parr, 2016, p. 1). As the emergence of nursing as an academic discipline, the literature is replete with descriptions of key nursing behaviours such as communication, relationship building, empathy and caring (Arnold \& Undermanboggs, 2011). However, it is frequently the case that these fundamental aspects of care that are often difficult to measure are drawn to our attention by their absence. Accounts of healthcare failures (Francis, 2013; Kirkup, 2015) suggest widespread and pervasive erosion of caring values across healthcare settings with worrying repercussions for the quality of patient care. Considering the important role nurses have in health care, policymakers, healthcare educators and the general public are becoming increasingly concerned about the values that nurses hold (Kitson, Muntlin Athlin, \& Conroy, 2014).

Specifically, patients' and relatives' complaints about health care focus on poor relationships/communication; a fact that is observed anecdotally in complaints departments internationally (Goodrich \& Cornwell, 2008). Analysis of some of these complaints reveals that for many complainants there is a lack of person-centred, personalised care that recognises each human being as an individual (Goodrich \& Cornwell, 2008). Indeed, a key emerging message from patient advocacy groups and associations such as "Patient Voices" is "look at me," "see me" and treat me as human (Patient Voices, 2015; The Patients Association, 2015). At the same time, calls within the nursing profession for a refocusing on the fundamental aspects of care represent the view that good nurse-patient and effective relationship building with clients and their families are essential components of modern health care (Kitson et al., 2014). Yet, good communication and supportive nurse-patient relationships require not only developing these skills, but also that the nurse is motivated by strong moral values in terms of respect, humanity and a fundamental desire to help others (Alfred et al., 2013). It is commonly recognised that, more than other occupations, nursing is a valuebased profession with a long history of a strong value-based core. Without embracing these values, their application in nursing care may be found lacking.

For years, nursing organisations internationally have sought to couch these important values within conceptual models that can

\section{What does this paper contribute to the wider global clinical community?}

- There is a dearth of research concerning nursing students' values, what influences these and whether or not they change over time. This study has demonstrated that empirical research on values in nursing is feasible and relevant.

- Despite concerns about today's nursing students' values, they appear to find honesty and altruism important.

- Concerns in health care internationally around competition between professionalism and altruism in nursing have been confirmed in this study.

- Concerns raised in reports on healthcare scandals around loyalty superseding honesty in healthcare accountability have also been confirmed in this study.

- The unclear role of religiosity in contemporary health care is reflected in the outcomes of this study, with about half of participants showing uncertainty or dislike around religiosity. Emanating from this finding is that cultural competence in regard to different religions and forms of spirituality may also be subject to uncertainty. This is not beneficial to patients.

- The approach of the Salford-Scott instrument to measure values in nursing has been reconfirmed as a promising means to addressing values in nursing practice research.

guide and inform nursing practice. For instance, the Canadian nun and nursing professor Simone Roach (Roach, 1987) argued for the inclusion of Six Cs (compassion, competence, confidence, conscience, commitment and comportment) of which the first one, compassion, was considered the most essential value. This approach was adapted for use in the UK (Cummings \& Bennett, 2012) and morphed into care, compassion, competence, communication, courage and commitment. Still compassion, as in "suffering with" (Cummings \& McPhail, 2014, p. 545), was considered essential. In Ireland, a condensed version highlights compassion, care and commitment, to translate core nursing values into practice (Department of Health, 2016). Tracing the origins of this to Roach's (1984) initial religion-informed formulation today is not so common. Overtly expressing Christian values is perhaps not in keeping with current secular approaches to health care and the pluralistic nature of contemporary society (Bradshaw, 2009). Terms such as caritas (Christian love of humankind), kindness 
and charity (Careful Nursing, 2014) are not as common as they used to be in describing nursing care. Nonetheless, with the need for value-based nursing reasserted frequently (Cummings \& McPhail, 2014), it is unsurprising that efforts to relate nursing to fundamental values embedded in religion, specifically altruism and honesty, are returning to the fore. More than overarching - and perhaps vaguevalues such as compassion, care and commitment (Department of Health, 2016), altruism and honesty are traditional "virtues" with transparent and undisputable implications for care. Altruism or selflessness motivates putting the interests of the patient before oneself. Honesty motivates avoiding all deceit as part of health care. While the absolute application of these values is subject to debate, their core guidance is important to quality health care. Whether they are included sufficiently in nursing education is questioned as part of more general concerns regarding the lack of a suitable framework to inform and guide nurses in establishing a moral and ethical foundation to underpin their care (Riklikiene, Karosas, \& Kaseliene, 2018).

\section{2 | BACKGROUND OF THE STUDY}

Professional identity formation for nurses begins during undergraduate nursing preparation and continues to develop thereafter throughout the career trajectory (Crigger \& Godfrey, 2014). Essential professional values for nursing are transferred from working within the culture of nursing in placement and internships, but are also taught within the classroom setting (Alfred et al., 2013). There is a growing awareness that today's society is more individualistic, puts more emphasis on self-interest, is more tolerant of deception and less imbued with honesty and altruism (Johnson, Haigh, \& Yates-Bolton, 2007; Norton-Taylor, 2011). This puts even more emphasis on the importance of a professional education and socialisation in which these values ought to be transmitted.

Much has been written about the market-driven problems in health care today, and the link with a loss of compassion and other values is often made (Bradshaw, 2009). The pressure on contemporary health care is such that many hospitals and other organisations have great difficulty to cope with the demands (Dewar \& Christley, 2013). As a result, novice nurses are often socialised in a system in which time pressure and staff shortages dominate. In this climate, the examples of care to aspire to are often highly task-oriented with less emphasis on person-centred care (Kitson et al., 2014, p. 313). So even if nursing students enter the nursing profession with strong moral and ethical values, these may be eroded by their exposure to the healthcare environments. Recent international studies have identified that, due to time restrictions, low nurse-patient ratios and other factors nurses tended to deprioritise less visible aspects of nursing such as communication, developing relationships and patient education (Aiken et al., 2012; Sasso, Bagnasco, \& Aleo, 2013; Sermeus et al., 2011). Nursing staff also tended to use language that signified their concern with getting their jobs done and demonstrated low levels of compassion (Crawford, Gilbert, Gilbert, Gale, \&
Harvey, 2013). Altruism and honesty are not particularly promoted under such circumstances.

On the other hand, several commentators have attributed the problem not to healthcare practice, but to nursing education. Specifically, the emergence of university-based education for nurses has been blamed. Some have argued that a more scientific approach to nursing education would negatively impact the notion of working "from the heart". However, there is no empirical evidence to suggest that education in evidence-based care and enhanced professional status have a negative impact in itself. A critical analysis of the UK university-based educational approach for example has been deemed fit for purpose (Willis, 2012). Moreover, Aiken et al.'s (2014) European study of nursing education suggests that the benefits of university education outweigh possible disadvantages and that "increased emphasis on bachelor education for nurses could reduce preventable hospital deaths" (Aiken et al., 2014, p. 1). Nevertheless, some nursing educators have suggested that Schools of Nursing may not always do enough to introduce and reinforce core nursing values such as altruism and honesty (Timmins and de Vries, 2015)

One of the possible steps in nursing education is to screen students upon entry to the profession to check whether or not they hold core compassionate values (Kitson et al., 2014). Some voices have emphasised that, instead of testing aspiring nurses after their education, this should be done before they start their studies. Why waste time, money and effort if a student is not cut out for the profession? This perspective tends to highlight the temperamental (or virtuous) aspect inherent in the student. Some studies have demonstrated that values such as compassion are inherent traits in nursing students and that many are drawn to the profession due to their caring tendencies (Eley, Eley, Bertello, \& Rogers-Clark, 2012). As it is, it is very difficult to gauge whether nursing students already subscribe to the core values of nursing or acquire these during their nursing education. In the ROI, nursing students receive no prior suitability screening and little is known about what drives them to choose the nursing profession.

It is hard to draw conclusions from the above. Perhaps both healthcare practice and education could do more to sustain valuebased nursing. What is evident is that more research is needed to investigate the role of values in practice and the development of nursing values in education. How nursing student perceives core values and their implications for practice is the focus of this study.

\subsection{Aims of the study}

This study is a pilot study established to identify the extent to which nursing students appreciate altruism, honesty and religiosity. Honesty and altruism are core nursing values (Altun, 2002). However, within the Irish context, it was relevant to also include religiosity. Until recently, religion played a central role in all aspects of Irish society, including health care. How religion is valued by nursing students at present would provide a meaningful consideration in relation to the background of their nursing values. The emphasis in the 
study is on measuring the extent to which these values are relevant in student nurses' perspective on life and care practice. As contrasting values and principles may be at odds in nursing care, the study also set out to identify which principles inform decision-making in practice more. A secondary aim was to identify the strength with which these values were supported at different stages in the nursing student's education. Thus, comparisons were made between students in each 4 years of their education.

In order to measure the degree to which values were considered important, the study made use of a validated instrument, the Salford-Scott Nursing Values questionnaire adapted by Johnson et al. (2007). This instrument has been developed to measure honesty, altruism, religiosity, self-confidence and intellectual values, in nurses and nursing students by asking them to respond to statements about nursing behaviour. The tool contains 57 Likert-type items (five-point always admire, usually admire, uncertain, usually dislike and always dislike). Validity and reliability (Cronbach alpha $=.83$ ) of the instrument have been established by Johnson et al. (2007). Moreover, translations of the instrument have also demonstrated good validity and reliability. The Italian translation was subjected to an elaborate validation study which showed high face validity and content validity, a high test-retest reliability $(r=.91)$ as well as higher internal consistency than the original (alpha $=.95$ and .87 for the two sections) (Mecugni, Albinelli, Pellegrin, \& Finotto, 2014). A Turkish translation and adaptation also showed high reliability and validity. Content validity was achieved with factor analysis confirming the variables in the measure (Ulusoy, Güler, Yıldırım, \& Demir, 2016). A Lithuanian translation showed an overall Cronbach alpha score of .72 (Riklikiene et al., 2018) which is acceptable. It was concluded that the measure was fit for purpose.

Two other available tools were considered. The Nursing Professional Values Scale (NPVS) (Weis \& Schank, 2000) showed reliability and validity in measuring caring, activism, trust, professionalism and justice in the United States. Translated version was validated in China (Lin \& Wang, 2010) and Korea (Moon, Kim, Kim, Kim, \& Lee, 2014). Yet, the tool did not focus overtly on altruism, honesty and religious values and was therefore considered not as suitable for this study. Another consideration was that the Salford-Scott was developed for UK nurses, who are perhaps more similar to the Irish student nurses than the American nurses for whom the NPVS was designed. A similar argument was an important consideration in deciding against the use of an original Korean instrument (Yeun, Kwon, \& Ahn, 2005), even though it had high reliability values. While the factors identified in the study (self-concept of the profession, social awareness, professionalism, nursing roles and originality of nursing) were of interest, their limited rooting in spiritual and altruistic tendencies made them less applicable to the purpose of this study. Many other tools were available for the measurement of overall nursing competency (see for instance Nilsson et al., 2014), but no other validated tools for the kind of nursing values relevant for this study were identified and only the Salford-Scott instrument highlighted religiosity as part of its focus.

\section{METHOD}

\section{1 | Sample}

The sample potentially included the full population of undergraduate nursing students in the Republic of Ireland in the year in which the study was conducted (2016). This population had been estimated at 5,520 on the basis of information obtained from the thirteen Universities/Institutes of Technology at which they studied. To give each person in this population a chance to participate, permission was requested from all Heads of Schools to access them via email. Once permission was obtained, an allocated gatekeeper forwarded an invitation email with a link to the Survey Monkey site hosting the survey. A reminder was sent after 2 weeks. A total of 158 students completed the survey in this period. This response rate provided a margin of error of 7.68 at a confidence level of $95 \%$. This means that the confidence interval for the responses was the percentage of participants' who provided a particular response + or $-7.68 \%$.

\section{2 | Ethics/Permissions}

The School of Nursing and Midwifery Ethics Committee Trinity College Dublin and Local Research Ethics Committees granted approval for the study. All the students and schools were informed about the aims and process of the research. Students took part in this study on a voluntary basis. The survey started with a page that contained information on the study and the request to give consent to the researchers to use the anonymous information provided by participants for publication. Unless participants ticked the box in which they gave consent, the website would not proceed to the next page. All information collected was processed in such a way that participants' identity could not be revealed.

\subsection{Survey instrument}

Permission was given to use and modify the previously published Salford-Scott Nursing Values questionnaire adapted by Johnson et al. (2007). The online survey (Survey Monkey ${ }^{\mathrm{TM}}$ ) developed for this study focused primarily on the values of honesty, altruism and religiosity. The questions presented participants with practical situations in which the values were expressed in behaviours observed in others. This avoided a direct probing into a person's own behaviour to reduce the extent to which responses might be motivated by social desirability. Fifteen primary Salford-Scott items which were focussing on honesty, altruism and religiosity were selected, of which eventually 12 items showed optimal internal consistency following reliability analysis (Cronbach alpha $=.72$ ). Furthermore, eight statements were included that specifically related to competition between relevant values and principles in nursing practice. These were presented as five-point Likert scales indicating degree of agreement-disagreement and provided insight into which values took precedence in the presented situations. These items were highly diverse, with 
TABLE 1 Demographics

\begin{tabular}{|c|c|c|c|c|}
\hline \multicolumn{5}{|c|}{ Demographics of the sample } \\
\hline Gender & Female (87\%) & Male (13\%) & & \\
\hline Age & $\begin{array}{l}17-20 \\
\text { years }(29 \%)\end{array}$ & $\begin{array}{l}21-30 \\
\text { years (51\%) }\end{array}$ & $\begin{array}{l}31-40 \\
\text { years (12\%) }\end{array}$ & $40+(7 \%)$ \\
\hline $\begin{array}{l}\text { Nursing } \\
\text { discipline }\end{array}$ & $\begin{array}{l}\text { General } \\
\text { nursing (59\%) }\end{array}$ & $\begin{array}{l}\text { Children's and } \\
\text { general (18\%) }\end{array}$ & $\begin{array}{l}\text { Psychiatric } \\
\text { nursing (17\%) }\end{array}$ & $\begin{array}{l}\text { Intellectual } \\
\text { disability nursing (6\%) }\end{array}$ \\
\hline $\begin{array}{l}\text { Progress } \\
\text { in studies }\end{array}$ & Year 1 (27\%) & Year 2 (21\%) & Year 3 (29\%) & Year 4 (23\%) \\
\hline Ethnicity & White Irish (89\%) & White other (5\%) & African (3\%) & Others (3\%) \\
\hline Religion & $\begin{array}{l}\text { Roman } \\
\text { Catholic (63\%) }\end{array}$ & Protestant (4\%) & $\begin{array}{l}\text { No religion, } \\
\text { agnostic, atheist, } \\
(23 \%)\end{array}$ & Unsure (6\%) (others: 4\%) \\
\hline
\end{tabular}

low internal consistency (Cronbach alpha $=.41$ ), and were therefore only analysed separately. In addition to these items, relevant demographics were solicited and the level of religiosity and religious behaviour was probed.

\subsection{Data analysis}

Descriptive statistics were produced for all variables using Survey Monkey, and further statistical analysis was performed using SPSS version 24 (IBM Corp 2017).

\section{4 | RESULTS}

\section{1 | Demographics}

One hundred and fifty-eight nursing student responses were received. The majority of the respondents were female $(87 \%$, $n=137$ ). And the distribution within age groups shows expectedly that $80 \%$ was between $17-30$ years old, with almost $20 \%$ mature students. A demographic profile of participants is reported in Table 1.

Most students were studying General Nursing (58.9\%, $n=93$ ). The remainder were from Children's and General Integrated programmes $(17.7 \%, n=28)$, Intellectual Disability Nursing programmes (6.3\%, $n=10$ ) and Psychiatric Nursing programmes (17.1\%, $n=27$ ). Most students identified as Roman Catholic (RC) $(63.3 \%, n=100)$, $23.2 \%$ reported to be agnostic, atheist or with no religion, and only $4 \%$ were of a protestant denomination. There were no students from the Jewish, Hindu or Muslim faiths. Most participants identified with White Irish nationality $(89.2 \%, n=141)$. African students accounted for $2.6 \%(n=4)$ of the cohort, and no Irish Travellers (a minority indigenous ethnic group in Ireland) were in the sample.

The response related to strength of religiosity/spirituality and frequency of practicing it is outlined in Table 2. The sample is more or less divided into one half of participants indicating strong or very strong religiosity or spirituality, while the other half reports weak of no religiosity/spirituality. As regards the frequency of religious practice, almost half of participants indicates practicing religion/ spirituality a few times per year, while about a quarter suggests more than once a week. With over $20 \%$ indicating not practicing ever, this is a move away from a weekly church attending sample we might have found in the past in Ireland.

\section{2 | Strength of honesty, altruism and religiosity}

Aggregate variables were computed for the three main variables providing the mean response to the 12 primary questions. Four questions represented each variable. The findings show that participants response to the items suggests they admired altruism $(m=4.13)$ most, followed by honesty $(m=3.81)$ and finally religiosity $(m=3.10)$. With scores ranging from 1 (always dislike)-5 (always admire), the tendency for altruism and honesty is in the 4 (usually admire) range, while the mean for religiosity is closest to 3 (uncertain). Kolmogorov-Smirnov tests demonstrated that the variables were not normally distributed. Hence, the Wilcoxon signed-rank test (nonparametric) was used and indicated that altruism was rated

TABLE 2 Strength of religiosity/spirituality and frequency of religious/spiritual practice

\begin{tabular}{|c|c|c|c|}
\hline \multicolumn{2}{|c|}{$\begin{array}{l}\text { How strongly religious or } \\
\text { spiritual do you consider } \\
\text { yourself to be? }\end{array}$} & \multicolumn{2}{|c|}{$\begin{array}{l}\text { About how often do you spend time on } \\
\text { religious or spiritual practices? }\end{array}$} \\
\hline $\begin{array}{l}\text { Response } \\
\text { categories }\end{array}$ & $\begin{array}{l}\text { Distribution } \\
n(\%)\end{array}$ & Response categories & $\begin{array}{l}\text { Distribution } \\
n(\%)\end{array}$ \\
\hline Strong & $21(13)$ & More than once per day & $10(6)$ \\
\hline $\begin{array}{l}\text { Somewhat } \\
\text { strong }\end{array}$ & $58(37)$ & More than once per week & $41(26)$ \\
\hline $\begin{array}{l}\text { Not very } \\
\text { strong }\end{array}$ & 49 (31) & A few times per year & $74(47)$ \\
\hline $\begin{array}{l}\text { Not } \\
\text { religious/ } \\
\text { spiritual } \\
\text { in any way }\end{array}$ & $28(18)$ & Never & $33(21)$ \\
\hline $\begin{array}{l}\text { l'd rather } \\
\text { not say }\end{array}$ & $2(1)$ & l'd rather not say & $0(0)$ \\
\hline Total & $158(100)$ & Total & $158(100)$ \\
\hline
\end{tabular}


TABLE 3 Response to Salford-Scott questions on honesty, altruism and religiosity (aggregate variables and response to specific questions)

\begin{tabular}{|c|c|c|c|c|c|c|}
\hline Statements ("reverse scored item) & $\begin{array}{l}\text { Mean (SD) } \\
(n=158)\end{array}$ & $\begin{array}{l}\text { Always } \\
\text { admire } \\
n(\%)\end{array}$ & $\begin{array}{l}\text { Usually } \\
\text { admire } \\
n(\%)\end{array}$ & $\begin{array}{l}\text { Uncertain } \\
n(\%)\end{array}$ & $\begin{array}{l}\text { Usually } \\
\text { dislike } \\
\text { n (\%) }\end{array}$ & $\begin{array}{l}\text { Always } \\
\text { dislike } \\
n(\%)\end{array}$ \\
\hline Honesty & $3.81(0.698)$ & & & & & \\
\hline Being dishonest in harmless ways* & $3.85(0.904)$ & $2(1)$ & $10(63)$ & $33(21)$ & $74(47)$ & $42(27)$ \\
\hline Never cheating, or have to do with cheating situations, even for a friend & $4.04(1.122)$ & $69(44)$ & $53(34)$ & $18(11)$ & $13(8)$ & $7(4)$ \\
\hline $\begin{array}{l}\text { Never telling a lie even though to do so } \\
\text { would make the situation more comfortable }\end{array}$ & $3.63(1.114)$ & $39(25)$ & $58(36)$ & 29 (19) & $29(18)$ & $4(3)$ \\
\hline Always telling the truth though it may hurt oneself and others & $3.74(0.966)$ & $35(22)$ & $72(46)$ & $33(21)$ & $19(12)$ & $3(2)$ \\
\hline Altruism & $4.13(0.536)$ & & & & & \\
\hline Refusing aid to people who don't deserve it* & $4.11(0.900)$ & $2(1)$ & $8(5)$ & $26(16)$ & $60(38)$ & $64(40)$ \\
\hline Helping another person to feel more secure even if you don't like them & $4.31(0.739)$ & $70(44)$ & $72(46)$ & $10(6)$ & $5(3)$ & $0(0)$ \\
\hline Being kind to people even if they do things contrary to one's beliefs & $4.41(0.723)$ & $81(51)$ & $64(40)$ & $9(6)$ & $2(1)$ & $1(1)$ \\
\hline Being devout in one's religious faith & $3.46(0.975)$ & $19(12)$ & $65(41)$ & $48(30)$ & $22(13)$ & $5(3)$ \\
\hline Always living out one's religion in daily life & $3.24(0.961)$ & $11(7)$ & $56(35)$ & $58(37)$ & $26(17)$ & $7(4)$ \\
\hline Encouraging others to attend religious services and lead religious lives & $2.38(1.021)$ & $3(1)$ & $24(15)$ & $47(30)$ & $40(25)$ & $44(28)$ \\
\hline Attending religious services regularly & $3.34(1.105)$ & $20(13)$ & $57(36)$ & $53(34)$ & $13(8)$ & $15(10)$ \\
\hline \multicolumn{7}{|l|}{ Excluded questions } \\
\hline $\begin{array}{l}\text { Helping a close friend get by in a tight situation, even though } \\
\text { one may have to stretch the truth a little to do it* (Honesty) }\end{array}$ & $2.23(0.945)$ & $31(20)$ & $81(51)$ & $27(18)$ & $16(10)$ & $3(2)$ \\
\hline Revenging wrongs that other people have done to you* (Altruism) & $3.96(0.957)$ & $2(1)$ & $14(9)$ & $21(13)$ & $72(46)$ & 49 (31) \\
\hline Being an atheist* (Religiosity) & $2.88(0.940)$ & $14(9)$ & $27(17)$ & $92(58)$ & $14(9)$ & $11(7)$ \\
\hline
\end{tabular}

significantly higher than honesty $(z=-4.86, p=.000)$ and religiosity $(z=-9.67, p=.000)$, with honesty also significantly higher than religiosity $(z=-7.65, p=.000)$. Interestingly, the penultimate question, in which participants were probed on their stance on encouraging others to attend religious services and lead religious lives, showed that nursing students mostly disapproved or were uncertain about this. Overall, the category "uncertain" was chosen more in relation to the religiosity items than for the altruism and honesty items (Table 3).

\section{3 | Correlations}

Spearman's correlations between the three variables were low. Nonetheless, two were significant. The correlation between religiosity and altruism was nonsignificant. This suggests that altruism could be admired without a religious tendency. The other two religiosity items querying the strength and frequency of practicing religious faith or spirituality correlated highly, also with the religiosity variable computed from the Salford-Scott items. However, they did not correlate significantly with altruism and honesty. Perhaps the most salient finding is that the stage (year 1-4) of the students' education was unrelated to any of the values. While this is only a cross-sectional finding, and we cannot make inferences of change across years, it is obvious that the stability of the scores over the years does not support the idea that nursing education would have a strong impact on these values in student nurses. As regards age, the small negative significant correlation with altruism suggests a possible reduction in altruism with age (Table 4).

\subsection{Competition between values}

The eight statements in which two competing values were presented (Table 5) provided a more in-depth perspective on how honesty, altruism and kindness fared when pitted against oppositional or contrasting values or principles such as self-interest, efficiency, opportunism, professionalism and individual moral responsibility (as opposed to rule-based morality). While honesty comes out as the prevailing value when in conflict with self-interest, it is evident from the other two items that honesty is not perceived as the highest priority for most participants. A similar effect is observed for altruism. Self-interest versus altruism suggests that, in the particular question posed, self-interest is supported more (50\%) than altruism (37\%). Professionalism also prevails when contrasted with altruism. This sobering perspective is perhaps somewhat tempered by the fact that over a quarter of the respondents were uncertain about this and also that, when it is between efficiency and kindness, the majority side with kindness. The last two items contrasted individual freedom and individual moral judgement against rule-based ethics and morals. In both cases, the participants chose in favour of individual morality. They preferred to be allowed to make up their own minds when 
TABLE 4 Spearman's correlations between main variables in the study

\begin{tabular}{|lc|} 
Correlations ( $\boldsymbol{n}=158)$ & $\begin{array}{l}\text { Spearman's rho } \\
(\boldsymbol{p} \text {-value) }\end{array}$ \\
\hline Religiosity-altruism & $.137(.086) \mathrm{ns}$ \\
\hline Religiosity-honesty & $.291(.000)^{* * *}$ \\
\hline Altruism-honesty & $.320(.000)^{* * *}$ \\
\hline Religiosity-strength religiosity & $.638(.000)^{* * *}$ \\
\hline Religiosity-religious practice & $.610(.000)^{* * *}$ \\
\hline Religious practice-strength religiosity & $.781(.000)^{* * *}$ \\
\hline Progress in education-religiosity & $.005(.957) \mathrm{ns}$ \\
\hline Progress in education-honesty & $.021(.797) \mathrm{ns}$ \\
\hline Progress in education-altruism & $-.045(.579) \mathrm{ns}$ \\
\hline Age-religiosity & $-.038(.635) \mathrm{ns}$ \\
\hline Age-honesty & $-.059(.463) \mathrm{ns}$ \\
\hline Age-altruism & $-.203(.011)^{*}$ \\
\hline
\end{tabular}

${ }^{*}$ Significance at .05 level.

${ }^{* * *}$ Significance at .001 level (2-tailed).

moral or ethical judgements had to be made, rather than having their decisions prescribed. In general, the extent to which participants reported to be uncertain suggests that many student nurses may be indecisive in situations like the ones presented in the questions.

\section{5 | DISCUSSION}

The data from this study reveal that, of the three primary values emphasised in this study (altruism, honesty and religiosity), nursing students admire altruism in health care most, followed by honesty and religiosity. The differences were statistically significant. The order is identical to the findings of Riklikiene et al. (2018). The level of support expressed for altruism was high. This is reassuring and in keeping with a traditional perspective of nursing (O'Neill, 1973) However, when altruism is stereotyped in a biblical sense as "good Samaritan" behaviour and contrasted with professionalism, the students admired professionalism more. This taps into an important contemporary issue in nursing. Often professionalism in nursing is seen as ensuring that all assigned tasks are completed and when under time pressure, this goes at the expense of the "soft" care elements exemplified in person-centred care (listening, being with the patient, answering questions, showing empathy, etc.) (Jones, Hamilton, \& Murry, 2015). Notwithstanding this, our study also showed that efficiency was not valued as much as kindness. Perhaps the precise phrasing of the questions can lead to different answers and therefore different conclusions about which value may affect practice more.

Not quite to the same extent as altruism, but honesty was admired by a majority of the nursing students in the study. Even so, it was also evident that the majority of participants felt that there might be good reasons not to be honest. It was intriguing that, if inconsistent with self-interest, honesty was considered more important in one case, but not in the other (see Table 5 first and sixth item). The nuance in the perspectives of the participants (see Table 5 second and third item) reflects the principle that dishonesty in health care may sometimes protect patients from overly harsh truths, (De Vries \& Timmins, 2016). In contrast with this, most participants (65\%) also thought they should tell patients the truth about their illness, which reflects a trend in medicine towards greater patient empowerment and truthfulness (Johnson et al., 2007). Interestingly, the present findings suggest more support for honesty than reported earlier (1983) in UK nursing student groups (Johnson et al., 2007).

Expressions of religiosity are admired by around half of participants, with about one-third expressing uncertainty. It is also evident that, where religiosity becomes proselytising, a majority of nursing students dislikes it. Overall, this is the value that participants are most uncertain about. Interestingly, this is also reflected in the reported intensity of religiosity or spirituality which is split in half between participants reporting strong or somewhat strong beliefs and those who considered their beliefs weak or absent. The medium-level correlations between the religion questions, strength or beliefs and frequency of religious practices suggest a coherent picture which reflects the current impact of religiosity in Irish society. While most people in the ROI report to have a religious faith (CSO, 2015), this is experienced within the context of an increasingly secular society (la Cour \& Hvidt, 2010; Zuckerman, 2009). The fact that religiosity and altruism in the present study were not significantly correlated fits into this pattern, and the suggestion emerges that religiosity did perhaps not inform the students' altruistic tendencies. It is possible that we are seeing an emphasis on a personal moral compass in these nursing students. This is also reflected in that participants mostly wanted to be allowed to make up their own minds about moral and ethical issues, rather than following a prescribed rule-based ethics.

\section{1 | Considerations for education}

The cross-sectional findings in this study do not provide insight into how values develop within nursing students over the course of their studies, in the way that a longitudinal study would. Still, the lack of variation between the results of the students across the 4 years of their studies is relevant. This is in contrast with Johnson et al.'s (2007) findings, which suggested that in 2005 students started their studies lower in altruism but increased in altruism over time, while students in 1983 followed an opposite trajectory. The findings of the present study do not confirm either trend and hence raise questions. For instance, is the strength of the values stable because nursing courses in Ireland do not attempt to optimise values in their curricula? There are indeed signs that cultural, religious and spiritual issues, while gaining increasing importance at a national level in ROI (HSE, 2009, 2011, Radford, 2008), receive limited attention in undergraduate nursing curricula (ABA, 2005). Alternatively, one might consider whether the values are stable across the 4 years, because 
TABLE 5 Agreement/disagreement with statements in which two competing values are presented in a nursing care context

\begin{tabular}{|c|c|c|c|c|c|c|c|}
\hline Statements & & $\begin{array}{l}\text { Strongly } \\
\text { agree } \\
n(\%)\end{array}$ & $\begin{array}{l}\text { Agree } \\
n(\%)\end{array}$ & $\begin{array}{l}\text { Uncertain } \\
n(\%)\end{array}$ & $\begin{array}{l}\text { Disagree } \\
n(\%)\end{array}$ & $\begin{array}{l}\text { Strongly } \\
\text { disagree } \\
n(\%)\end{array}$ & \\
\hline $\begin{array}{l}\text { As disciplinary action can be quite severe, it is best } \\
\text { for nurses to keep quiet about minor mistakes that } \\
\text { cause no real harm }\end{array}$ & Self-interest & $0(0)$ & $15(10)$ & 25 (16) & $66(42)$ & $52(33)$ & Honesty \\
\hline $\begin{array}{l}\text { Whether a lie is permissible or not permissible } \\
\text { totally depends on the situation }\end{array}$ & Opportunism & $14(9)$ & $56(35)$ & $39(25)$ & $37(23)$ & $11(7)$ & Honesty \\
\hline $\begin{array}{l}\text { Being calm and efficient is more important than being } \\
\text { kind when you are very busy on the ward }\end{array}$ & Efficiency & $8(5)$ & $24(15)$ & 27 (17) & $81(51)$ & 18 (11) & Kindness \\
\hline $\begin{array}{l}\text { Nursing needs to drop the vocational "good Samaritan" } \\
\text { image and aim to be a skilled professional job }\end{array}$ & Professionalism & $33(21)$ & $43(27)$ & $42(27)$ & $31(20)$ & $9(6)$ & Altruism \\
\hline $\begin{array}{l}\text { Creating strict codes of ethics that prevent certain types of } \\
\text { actions could stand in the way of better human relationships } \\
\text { and individual flourishing }\end{array}$ & $\begin{array}{l}\text { Human } \\
\text { relations }\end{array}$ & 19 (12) & $61(39$ & $44(28)$ & 27 (17) & $7(4)$ & $\begin{array}{l}\text { Rule-based } \\
\text { ethics }\end{array}$ \\
\hline
\end{tabular}

nursing students might be drawn to the profession already imbued with these values. Conceptually, perhaps more attention should be paid to what extent a value such as altruism should be perceived as an enduring "trait" or a "state" subject to fluctuations. This is by no means a trivial matter, considering the concerns within the profession that registered nurses are found lacking in values and whether to address this as part of recruitment and selection or through education (Rolfe \& Gardner, 2014).

This is an important consideration for future educators of nurses, also because of the growing ethnic and religious diversity among patients which requires personalised attention. The impression is emerging that nurses often provide spiritual care to patients based on their own beliefs, but without sufficient education and training to understand patients with a different spiritual or religious background (McSherry \& Jamieson, 2011; Timmins, 2013). It is a concern that such support may be ineffective and deprive patients of opportunities to have their own spiritual supports system validated. Nursing educators are in an ideal position to provide sufficient education and training in this area so that future nurses can manage their own beliefs in this context (Van Leeuwen, Tiesinga, Post, \& Jochemsen, 2006) and are competent in providing support to patients from a wide variety of religious and spiritual backgrounds.

\section{2 | Considerations for the Salford-Scott instrument}

It is very common that, once an instrument is validated, the development process stops, for fear that further tinkering would make comparisons between studies hard. As a result, initial nonfatal flaws to instruments are often left unaddressed. Also, updates to a changing social or occupational environment fail to emerge. Fortunately, research on the Salford-Scott tool is ongoing and includes adaptations (Johnson et al., 2007) and translations (Mecugni et al., 2014; Riklikiene et al., 2018; Ulusoy et al., 2016). The present adaptation used in this study has also revealed important aspects of the instrument that has implication for its use in future.

First and foremost, from a methodological perspective, it was important to discriminate between questions that address values more or less in isolation (Table 3) and those questions that include competition between two values (Table 5). The 12 primary questions included in the analysis provide the most reliable measure of the strength of values held by participants. The internal consistency findings (Cronbach alpha $=.72$ ) supports this. The eight questions in which competing values were presented suggest which values are prioritised in practice. Together, these provide important indications of the role of values in relation to the complex demands of nursing today. The competition between contrasting values was not made explicit in the original design of the instrument, but is essential for our understanding of its outcomes. The present adaptation suggests a reconceptualisation of the tool in this respect.

This issue comes to light most clearly when we observe the three primary questions which were excluded from the analysis because they significantly reduced the internal consistency of the tool (Table 3). The possible reasons for this are the implicit competition with other values, which affects face validity, construct validity and social desirability.

The excluded honesty question (Table 3) suggests competition between loyalty and honesty, in which case loyalty prevails. It is highly likely that this will have affected the negative impact on the internal consistency of the instrument. Which is not to say that the 
question itself is not relevant. Competition between loyalty and honesty often occurs in disciplinary hearings in hospitals or investigations into malpractice or medical mistakes and may lead to long drawn out procedures to get to the root of the issue. Such loyalty, motivating reluctance in staff to "sell one another out", while admirable in one sense, is problematic in health care, as detailed in the Francis Report (2013) and reports on other scandals. The problem is also at the core of "group think", the process whereby extreme loyalty and conformity leads to unchallenged and ultimately poor decision-making in organisations, sometimes with disastrous outcomes (Janis, 2015). The excluded altruism question (Table 3) brings in the use of the term "revenge" as opposite to altruism, where self-interest would have been more appropriate. This reduces the construct validity, but even at face value, it is questionable. Also, the strong negative connotations of the word "revenge" will have affected the response disproportionately. Finally, the excluded religion question used the term "atheism" which is not inappropriate in a reverse question, but its contemporary connotations are such that participants may have found it hard to admit agreeing with it, for reasons of social desirability. The fact that $58 \%$ of participants expressed uncertainty in response to this question suggests as much. It is unfortunate that each of these questions was reverse items. As a result of this, only two reverse items remained part of the adapted instrument included in the analysis. There is scope to reverse three of the remaining questions to make up for this problem. In the light of the discussion above, it is worth considering the inclusion of a social desirability scale within the instrument to identify participants who are overly concerned with how they come across. There is also scope to further analyse all items and identify and distinguish between unidirectional values, bidimensional values and competing values in contemporary health care.

\subsection{Strengths and limitations}

The sample size $(n=158)$, while in itself acceptable, is lower than was hoped for. Hence, our results should be treated with caution. A confidence interval of \pm 7.68 is a bit higher than desirable but far from unacceptable considering the modest ambitions of this pilot study. A confidence interval of \pm 5.00 would have been standard and would have been achieved with a sample of $n=359$. The achieved response rate $(n=158$, which is under $3 \%$ of the total population of 5,520 nursing students) seems disappointing, but needs to be seen in relation to the fact that the desired sample size of $n=359$ would also only have provided a $6.5 \%$ response rate. To put this further in perspective, it needs to be appreciated that the sampling had been highly ambitious to include the whole target population. If the same number of responses had been received by handing out the questionnaire among nursing students in different locations, we would have had the same statistical power and confidence interval, but we could have boasted a $90 \%$ 95\% response rate if only a few of the students who were approached had refused to participate. Therefore, computing the response rate from all who could have participated, while correct in principle, makes the sample look more questionable than it is. As Templeton, Deehan, Taylor, Drummond, and Strang (1997) posited, a low survey response need not necessarily be a fatal study flaw, particularly when little is known about the topic and the aim is exploratory (Templeton et al., 1997). Finally, it needs to be considered that an impersonal email invitation is not generally construed as a personal invitation to participate in a study. It is halfway between an announcement on a noticeboard and a personal letter. Limitations in the effectiveness of research recruitment via email are not a unique feature of our study and reflect the contemporary international literature (Koo \& Skinner, 2005). Other online platforms or recruitment via mobile phone may at present be more successful (O'Connor, Jackson, Goldsmith, \& Skirton, 2013).

Secondly, a general and unavoidable bias affecting almost all survey-based research is that participants who respond to an open recruitment effort for a study often do so because of an interest in research studies, a need to have their voice heard, or a particular interest in the topic. Each of these motivations may have affected the outcomes, although it is impossible to identify how.

A third limitation of the study is related to the psychological sensitivity around the values the questions in the survey pertained to. It is possible that those students who did respond did so in a socially desirable way. There are signs in the responses (see above) that some terminology in the questions (atheism and revenge) and their connotations may have triggered socially desirable responses, which may have affected the reliability. And while three questions were excluded in which this impact was evident, more subtle effects may still have impacted the outcomes here and there.

Finally, while the sample would appear, for as much as the limited demographic information permits, to be largely representative of the population of student nurses in the Republic of Ireland, this does not extend to the present population of nurses in general. In particular, limited involvement of minority or immigrant groups who represent a growing segment of all nurses means that we must abstain from making this type of generalisation. It is evident that their perspective on values is important, having been raised within societies with different traditions and how this has affected nursing in Ireland would be of great interest. More personal recruitment methods may need to be included to motivate these groupings to be involved. Perhaps this can count as a more general point for future recruitment efforts within the nursing student population.

\section{6 | CONCLUSION}

This is the first-ever study of fundamental values in nursing students in the Republic of Ireland. The findings show that, in particular, the values of altruism and honesty are still embraced by the participants and considered of great importance. This can be seen as reassuring for the profession as a whole. The nursing profession in the ROI may still attract students who find altruism and honesty important, but whether the nursing courses they attend adds to how the students experience these values is not at all obvious. In relation to 
religiosity, the support is not equivocal. Within the context of widespread secularism, many nursing students profess to be religious or spiritual, but while admiration for religiosity is common, so is uncertainty. The low and/or insignificant correlations between altruism, honesty and religiosity suggests that these are not part of one value package and that nursing students have separate perspectives on each value. When competition between different values in nursing care appears, students may prioritise professionalism over altruism, consider honesty on a case by case basis and prefer moral autonomy over rule-based ethics.

While the reliability of Salford-Scott instrument has been supported in several studies (Johnson et al., 2007; Mecugni et al., 2014; Riklikiene et al., 2018; Ulusoy et al., 2016) including the present one, it is evident that the twenty-question adaptation employed has yielded new perspectives on the conceptualisation of the tool. It would seem that there is scope to discriminate more transparently between questions that measure the strength of values in isolation and questions which compare competing values in practical care situations. The latter approach shows promise in adding significantly to our understanding of how values inform nursing care in practice.

\section{7 | IMPLICATIONS AND RECOMMENDATIONS FOR PRACTICE AND FURTHER RESEARCH}

Nursing is a value-based profession, and nursing is fundamentally about helping others. Professional identity formation for nurses begins during undergraduate nursing preparation and continues to develop thereafter throughout the career trajectory. As such the adoption, development and application of these core values, including moral and ethical responsibilities, are essential components of professional nursing socialisation. Recent concerns with substandard care have revisited value-based care suggesting that those entering the profession, in some countries at least, ought to intrinsically exhibit values aligned with nursing from the outset of their education rather than being taught. This study confirmed that today's nursing students in Ireland find altruism and honesty highly important and seem to do so in a stable fashion from entering their education. And while many students expressed religiosity and spirituality, this was only marginally related to levels of altruism and honesty expressed. It would seem that from this perspective there is no reason to feel nostalgic about the days when hospitals were run by religious orders.

Considerations for further research into values among the nursing community might make use of the (adapted) Salford-Scott Nursing Values Questionnaire. In particular, the questions that address competing values suggest a strong model for investigating how values are expressed in nursing practice. Moreover, it would be of great interest to identify how this relates to actual care behaviours and patient outcomes. A further adaptation taking into account the Six C's in the UK, or compassion, care and commitment in the ROI could be developed to add to the relevance of this area of empirical study.

\section{CONTRIBUTIONS}

Study design: FT, CK, JDV, MJ, JGC, CH; data collection and analysis: $\mathrm{FT}$, JDV, $\mathrm{MJ}, \mathrm{CH}$; and manuscript preparation: FT, JDV, MJ, JGC, $\mathrm{CH}$.

\section{ORCID}

Fiona Timmins (iD http://orcid.org/0000-0002-7233-9412

\section{REFERENCES}

Aiken, L. H., Sermeus, W., Van den Heede, K., Sloane, D. M., Busse, R., McKee, M., ... Kutney-Lee, A. (2012). Patient safety, satisfaction, and quality of hospital care: Cross sectional surveys of nurses and patients in 12 countries in Europe and the United States. British Medical Journal, 344, e1717. https://doi.org/10.1136/bmj.e1717

Aiken, L. H., Sloane, D. M., Bruyneel, L., Van den Heede, K., Griffiths, P., Busse, R., ... RN4CAST Consortium (2014). Nurse staffing and education and hospital mortality in nine European countries: A retrospective observational study. Lancet, 383(9931), 1824-1830. https://doi. org/10.1016/S0140-6736(13)62631-8

Alfred, D., Yarbrough, S., Martin, P., Mink, J., Lin, Y. H., \& Wang, L. S. (2013). Comparison of professional values of Taiwanese and United States nursing students. Nursing Ethics, 20(8), 917-926. https://doi. org/10.1177/0969733013484486

Altun, I. (2002). Burnout and nurses' professional and professional values. Nursing Ethics, 9, 269-278. https://doi.org/10.1191/0969733002ne 5090 a

An Bord Altranais (2005). An Bord Altranais requirements and standards for nurse registration education programmes. Dublin, Ireland: An Bord Altranais.

Arnold, E., \& Undermanboggs, K. (2011). Interpersonal relationships-professional communication skills for nurses (6th ed.). St Louis, MO: Saunders.

Bradshaw, A. (2009). Measuring nursing care and compassion: The McDonaldised nurse? Journal of Medical Ethics, 35, 465-468. https://doi.org/10.1136/jme.2008.028530

Careful Nursing (2014). Careful nursing. Retrieved from http://www.caref ulnursing.ie/carefulnursing-caritas

Central Statistics Office (2015). Persons usually resident and present in the state on census night, classified by place of birth and age group, 2011. Retrieved from http://www.cso.ie/multiquicktables/quickTables.aspx? id $=$ cdd 22

Crawford, P., Gilbert, P., Gilbert, J., Gale, C., \& Harvey, K. (2013). The language of compassion in acute mental health care. Qualitative Health Research, 23(6), 719-727. https://doi.org/10.1177/104973231348 2190

Crigger, N., \& Godfrey, N. (2014). From the inside out: A new approach to teaching professional identity formation and professional ethics. Journal of Professional Nursing, 201430(5), 376-382. https://doi.org/ 10.1016/j.profnurs.2014.03.004

Cummings, J., \& Bennett, V. (2012). Compassion in practice: Nursing, midwifery and care staff: Our vision and strategy. London, UK: NHS Commissioning Board, London.

Cummings, J., \& McPhail, S. (2014). Compassion in practice: A contagious condition. British Journal of Healthcare Assistants, 8(11), 544-549. https://doi.org/10.12968/bjha.2014.8.11.544 
De Vries, J., \& Timmins, F. (2016). Deception and self-deception in health care. Nursing Philosophy, 17(3), 163-172. https://doi.org/10.1111/ nup.12126

Department of Health (2016). Values for nurses and midwifes in Ireland. Department of Health Position Paper. Dublin, Ireland: Department of Health. Retrieved from www.heatlh.gov.ie

Dewar, B., \& Christley, Y. (2013). A critical analysis of compassion in practice. Nursing Standard, 28(10), 46-50. https://doi.org/10.7748/ ns2013.11.28.10.46.e7828

Eley, D., Eley, R., Bertello, M., \& Rogers-Clark, M. (2012). Why did I become a nurse? Personality traits and reasons for entering nursing. Journal of Advanced Nursing, 68(4), 1546-1555. https://doi.org/10. 1111/j.1365-2648.2012.05955.x

Francis, R. (2013). Report of the Mid Staffordshire NHS Foundation Trust Public Inquiry. Norwich, UK: The Stationery Office. Retrieved from http://www.midstaffspublicinquiry.com

Goodrich, J., \& Cornwell, J. (2008). Seeing the person in the patient. The Point of Care review paper. London, UK: The Kings Fund.

Health Service Executive (2011). A question of faith - The relevance of faith and spirituality in health care. Dublin, Ireland: Health Service Executive.

Health Services Executive (HSE) (2009). Health services intercultural guide: Responding to the needs of diverse religious communities and cultures in healthcare settings. Dublin, Ireland: HSE. Retrieved from http://www. hse.ie/eng/services/Publications/services/Sociallnclusion/Intercultura IGuide/Traditional/

IBM Corp (2017). IBM SPSS statistics: Version 24. Chicago, IL: IBM Corporation.

Janis, I. L. (2015). Groupthink: The desperate drive for consensus at any cost. In J. M. Shafritz, J. S. Ott \& Y. S. Jang (Eds.), Classics of organization theory (8th ed., pp. 161-168). Boston, MA: Cengage Learning.

Johnson, M., Haigh, C., \& Yates-Bolton, N. (2007). Valuing of altruism and honesty in nursing students: A two-decade replication study. Journal of Advanced Nursing, 57(4), 366-374. https://doi.org/10. 1111/j.1365-2648.2007.04119.x

Jones, T. L., Hamilton, P., \& Murry, N. (2015). Unfinished nursing care, missed care, and implicitly rationed care: State of the science review. International Journal of Nursing Studies, 52(6), 1121-1137. https://doi. org/10.1016/j.ijnurstu.2015.02.012

Koo, M., \& Skinner, H. (2005). Challenges of internet recruitment: A Case Study with Disappointing Results. Journal of Medical Internet Research, 7(1), e6. https://doi.org/10.2196/jmir.7.1.e6

Kirkup (2015). The report of the Morecambe Bay investigation. Copyright 2015. Retrieved from https://www.gov.uk/government/uploads/sys tem/uploads/attachment_data/file/408480/47487_MBI_Accessible_ v0.1.pdf

Kitson, A. L., Muntlin Athlin, A., \& Conroy, T. (2014). Anything but basic: Nursing's challenge in meeting patients' fundamental care needs. Journal of Nursing Scholarship, 46(5), 331-339. https://doi.org/10. 1111/jnu.12081

Kitson, A. L., Sørensen, E. E., Jeffs, L., \& Parr, J. (2016). Call for papers. Journal of Clinical Nursing. Retrieved from http://onlinelibrary.wiley.c om/journal/10.1111/(ISSN)1365-2702

la Cour, P., \& Hvidt, N. C. H. (2010). Research on meaning-making and health in secular society: Secular, spiritual and religious existential orientation. Social Science and Medicine, 71, 1292-1299. https://doi.org/ 10.1016/j.socscimed.2010.06.024

Lin, Y. H., \& Wang, L. S. (2010). A Chinese version of the revised Nurse Professional Values Scale: Reliability and validity assessment. Nurse Education Today, 30, 492-498. https://doi.org/10.1016/j.nedt.2009. 10.016

McSherry, W., \& Jamieson, S. (2011). An online survey of nurses' perceptions of spirituality and spiritual care. Journal of Clinical Nursing, 20
(11-12), 1757-1767. https://doi.org/10.1111/j.1365-2702.2010. 03547.x

Mecugni, D., Albinelli, P., Pellegrin, J., \& Finotto, S. (2014). The Italian validation of the Salford-Scott nursing values questionnaire. Nursing Ethics, 22(2), 248-260.

Moon, S., Kim, D. H., Kim, E. J., Kim, Y. J., \& Lee, S. (2014). Evaluation of the validity and reliability of the Korean version of the Nursing Professional Values Scale-Revised. Nurse Education Today, 34(3), 325330. https://doi.org/10.1016/j.nedt.2013.06.014

Nilsson, J., Johansson, E., Egmar, A. C., Florin, J., Leksell, J., Lepp, M., ... Carlsson, M. (2014). Development and validation of a new tool measuring nurses self-reported professional competence-The nurse professional competence (NPC) Scale. Nurse Education Today, 34(4), 574-580. https://doi.org/10.1016/j.nedt.2013.07.016

Norton-Taylor, R. (2011). Military can show society the way on moral values and ethics, says Dannatt. The Guardian, 8 November 2011, Retrieved from http://www.theguardian.com/uk/2011/nov/08/milita ry-moral-values-ethics-dannatt

O'Connor, A., Jackson, L., Goldsmith, L., \& Skirton, H. (2013). Can I get a retweet please? Health research recruitment and the Twittersphere. Journal of Advanced Nursing, 70(3), 599-609. https://doi.org/10. 1111/jan.12222

O'Neill, M. (1973). A study of baccalaureate nursing students' values. Nursing Research, 22, 437-443.

Patient Voices (2015). http://www.patientvoices.org.uk/index.htm

Radford, K. (2008). Health, faith and equality prepared for the Health Research Board through building partnerships for Healthier Society Research Award. Dublin, Ireland: Health Research Board/Irish School of Ecumenics, Trinity College Dublin.

Riklikiene, O., Karosas, L., \& Kaseliene, S. (2018). General and professional values of student nurses and nurse educators. Journal of advanced nursing, 74(3), 666-676.

Roach, M. S., \& Canadian Hospital Association (1987). The Human Act of caring a blueprint for the health professions. Ottawa, ON: Canadian Hospital Association.

Rolfe, G., \& Gardner, L. (2014). The compassion deficit and what to do about it: A response to Paley. Nursing Philosophy, 15(4), 288-297. https://doi.org/10.1111/nup.12068

Sasso, L., Bagnasco, A., \& Aleo, G. (2013). Science for action based nursing. Journal of Advanced Nursing, 69, 2373-2374. https://doi.org/10. 1111/jan.12131

Sermeus, W., Aiken, L. H., Van den Heede, K., Rafferty, A. M., Griffiths, P., Moreno-Casbas, M. T., ... RN4CAST Consortium (2011). Nurse forecasting in Europe (RN4CAST): Rationale, design and methodology. BMC Nursing, 10(1), 6. https://doi.org/10.1186/1472-6955-10-6

Templeton, L., Deehan, A., Taylor, C., Drummond, C., \& Strang, J. (1997). Surveying general practitioners: Does a low response rate matter? British Journal of General Practice, 47(415), 91-94.

The Patients Association (UK) (2015). The Patients Association. Retrieved from http://www.patients-association.org.uk

Timmins, F. (2013). Nurse's views of spirituality and spiritual care provision in the Republic of Ireland. Journal for the Study of Spirituality, 3 (2), 121-137.

Timmins, F., \& de Vries, J. (2015). Follow the yellow brick road-the compassion deficit debate where to from here? Journal of clinical nursing, 24, 2689-2694.

Ulusoy, H., Güler, G., Yıldırım, G., \& Demir, E. (2016). Reliability and validity of the Salford-Scott nursing values questionnaire in Turkish. Nursing Ethics, 25(1), 80-91. https://doi.org/10.1177/09697330166 42626

Van Leeuwen, L., Tiesinga, J., Post, D., \& Jochemsen, H. (2006). Spiritual care: Implications for nurses' professional responsibility. Journal of Clinical Nursing, 15(7), 875-884. https://doi.org/10.1111/j.13652702.2006.01615.x 
Weis, D., \& Schank, M. J. (2000). An instrument to measure professional nursing values. Journal of Nursing Scholarship, 32(2), 201-204. https://doi.org/10.1111/j.1547-5069.2000.00201.x

Willis, P. (2012). Quality with compassion: the future of nursing education. Report of the Willis Commission on Nursing Education, 2012. Royal College of Nursing on behalf of the independent Willis Commission on Nursing Education 56. Retrieved from www. williscommission.org.uk, www.rcn.org.uk/williscommission

Yeun, E. J., Kwon, Y. M., \& Ahn, O. H. (2005). Development of a nursing professional values scale. Journal of Korean Academy of Nursing, 35(6), 1091-1100. https://doi.org/10.4040/jkan.2005.35.6.1091
Zuckerman, P. (2009). Why are the Danes and Swedes so irreligious? Nordic Journal of Religion and Society, 22(1), 55-69.

How to cite this article: Timmins F, King C, de Vries JMA, Johnson M, Cullen JG, Haigh C. Altruism, honesty and religiosity in nursing students. J Clin Nurs. 2018;27:36873698. https://doi.org/10.1111/jocn.14374 